\title{
The Wendelstein 7-X trim coil system
}

\author{
Thomas Rummel, Konrad Riße, Frank Füllenbach, Matthias Köppen, Johann Kißlinger, Tom Brown, Ron Hatcher, \\ Stephen Langish, Mike Mardenfeld, and Hutch Neilson
}

\begin{abstract}
The magnet system of the fusion experimental device Wendelstein $7-X(W 7-X)$ contains superconducting as well as normal conducting coils. Seventy superconducting coils are forming the steady state main field to confine the plasma. Inside of the plasma vessel ten control coils, made of copper, will be placed to modify the strike points of the plasma at the divertor. In addition a set of five normal conducting, water cooled trim coils will increase the experimental flexibility by providing a means to balance the divertor heat loads among the five field periods. The coils will be placed at the outer surface of the cryostat of W7-X. There are four coils (type A) with equal shape the fifth coil (type B) has a slightly different shape due to space restrictions. The coils have dimensions of 3.5x3.3 meters with 48 turns and will be operated with currents of up to $1.8 \mathrm{kA}$ (type A). The other coil (type B) has a smaller size of 2.8x2.2 meters, compensated by a higher number of turns and a higher operation current of $1.95 \mathrm{kA}$. Five independent power supplies are being fabricated to operate the coils with a maximum of flexibility. The concept is based on four-quadrant power supplies using Insulated-Gate-Bipolar-Transistors.

The trim coil package consisting of the five coils plus the five power supplies is being designed and built in collaboration between IPP, Germany and PPPL, USA, partly funded by the Department of Energy.
\end{abstract}

Index Terms-Wendelstein 7-X, trim coils, power supplies

\section{INTRODUCTION}

$\mathrm{T}$

HE MAGNET SYSTEM of the fusion experiment Wendelstein 7-X (W7-X) contains superconducting as well as normal conducting coils. Fifty three-dimensionally shaped superconducting coils are forming the fivefold symmetrical main field; twenty planar superconducting coils allow a variation of the shape of the plasma. Inside of the plasma vessel ten control coils made of copper will be placed to modify the strike points of the plasma at the divertor. In addition five normal conducting trim coils will increase the experimental flexibility by providing a tool to balance the divertor heat loads and also allow the correction of error fields. The trim coil project is conducted in close collaboration between the Princeton Plasma Physics Laboratory (PPPL) and the Max-Planck-Institute for Plasma Physics Greifswald (IPP). The coils and the DC power supplies are being manufactured by industry under contract to PPPL. IPP is providing the trim coil support elements, the assembly of the coils and power supplies as well as the infrastructure to support the coils such as the $1600 \mathrm{kVA}$ input transformers and coil and power supply cooling system.

\section{Motivation FOR TRIM COILS}

During fabrication and assembly of the W7-X superconducting main field coils high effort was spent to keep tolerances small. However, even small deviations from the ideal shape and position of the coils along with other influences, like the presence of minor quantities of ferromagnetic material or the unavoidable deformation of the support structures during operation of the machine, will result in magnetic field errors [1]. Trim coils can be used to provide strong individual field components which, together with the ten control coils in the plasma vessel, accomplish the compensation of errors field. The purpose of the trim coils is not only the correction of errors field. They also increase the experimental flexibility in terms of investigations of the effects of magnetic islands on the magnetic confinement and by influencing the helical plasma axis.

\section{TRIM COILS}

\section{A. Design}

The decision about the trim coils was made too late to introduce them into the cryostat and make them superconducting. Therefore a place at the outside of the cryostat had to be found. The arrangement of ports along the external side of the cryostat differs from module to module. Thus the trim coils had to be designed to avoid areas where ports in the cryostat are placed. This results in two different coil types (Fig. 1).

Four coils (type A) are identical in size and shape. They have overall dimensions of $3.5 \times 3.3$ meters with 48 turns and will be

Manuscript received July 15, 2013. This work was supported in part by the U.S. Department of Energy.

Th. Rummel, K. Riße, F. Füllenbach, M. Köppen, and J. Kißlinger are with the Max-Planck-Institute for Plasma Physics, 17491 Greifswald, Germany, (corresponding author phone: +49 383488 2778; fax: +49 383488 2709; e-mail: thomas.rummel@ipp.mpg.de).

T. Brown, R. Hatcher, S. Langish, M. Mardenfeld and H. Neilson, are with Princeton Plasma Physics Laboratory, Princeton, NJ 08543 USA, (e-mail: hneilson@pppl.gov). 
operated with currents of up to $1.8 \mathrm{kA}$. The trim coil type B is smaller (2.8x2.2 meters) than the type A coils, but has more turns (72) and will be operated at higher currents (up to $1.95 \mathrm{kA}$ ). Table 1 lists the final design parameters of the coils. Like all the other coils in W7-X, the trim coils are designed for steady state operation of up to 30 minutes. Both types of trim coils are made of eight pancakes. The type A coil has six turns per pancake and the type B coil has nine turns per pancake. The vacuum pressure impregnated insulation is based on glass tapes and epoxy and cyanate ester [2], [3].

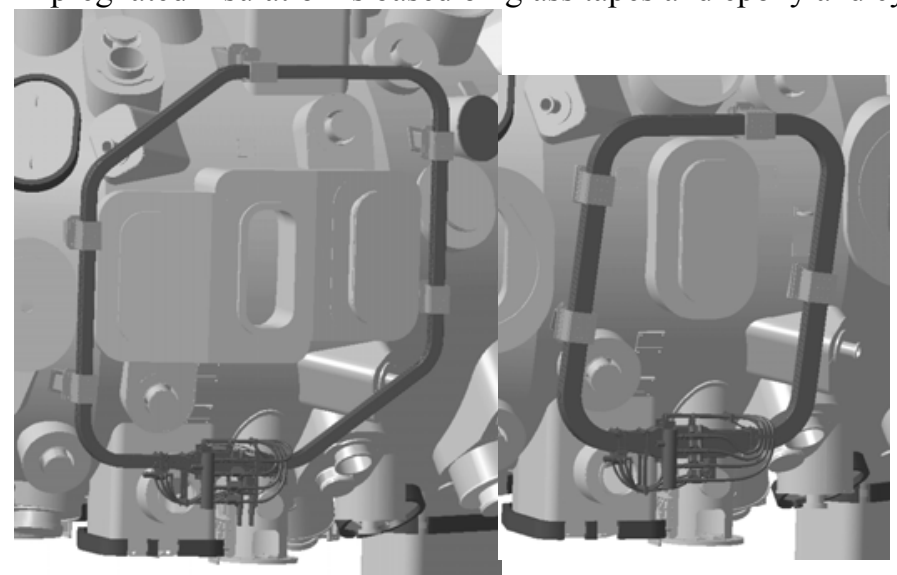

Fig. 1. Trim coils (left: type A, right: type B).

The cooling of the coils will be achieved by de-ionized water with a conductivity of about $5 \mu \mathrm{S} / \mathrm{cm}$. In order to keep the pressure drop down, all eight pancakes of a coil are hydraulically connected in parallel. At maximum current, a temperature rise of $30 \mathrm{~K}$ over the coil during operation has been calculated [4].

TABLE 1 DESIGN PARAMETERS OF THE TRIM COILS

\begin{tabular}{|c|c|c|}
\hline Designation & Type A Coil & Type B Coil \\
\hline No. of turns. & 48 & 72 \\
\hline Inductance & $19 \mathrm{mH}$ & $26 \mathrm{mH}$ \\
\hline Resistance@20 C & $53 \mathrm{~m} \Omega$ & $59 \mathrm{~m} \Omega$ \\
\hline Resistance@60 C & $62 \mathrm{~m} \Omega$ & $68 \mathrm{~m} \Omega$ \\
\hline Power loss & $200 \mathrm{~kW}$ & $260 \mathrm{~kW}$ \\
\hline Operation current & $+/-1800 \mathrm{~A}$ & $+/-1950 \mathrm{~A}$ \\
\hline Water pressure drop & 5.3 bar & 9.9 bar \\
\hline Water flow & $5.7 \mathrm{~m}^{3} / \mathrm{h}$ & $6.8 \mathrm{~m}^{3} / \mathrm{h}$ \\
\hline Conductor material & \multicolumn{2}{|c|}{ Copper (ASTM B188 UNS C10200 } \\
\hline Conductor dimensions & \multicolumn{2}{|c|}{$16.26 \mathrm{~mm} \times 16.26 \mathrm{~mm}$} \\
\hline Conductor cross section & \multicolumn{2}{|c|}{$180 \mathrm{~mm}^{2}$} \\
\hline Cooling channel diameter & \multicolumn{2}{|c|}{$10.16 \mathrm{~mm}$} \\
\hline Test voltage to ground & \multicolumn{2}{|c|}{$2 \mathrm{kV}$ d.c. } \\
\hline Insulation resistance to ground & \multicolumn{2}{|c|}{$1 \mathrm{G} \Omega$} \\
\hline
\end{tabular}

\section{B. Fabrication and Test}

The contract for the manufacturing of the coils was awarded to Everson Tesla Inc (ETI), located in Nazareth, PA, USA. The conductor was ordered by PPPL and furnished to ETI.

The main steps in the manufacturing are the preparation of the conductor, the winding of the coil, the vacuum pressure impregnation and the installation of the coil service components like water distribution and the current lead area.

In order to avoid repeated bending of the conductor, the preparation, i.e. sand blasting and priming, were done when the conductor was still uncoiled. The taping machine was placed next to the rotating winding table, so that the conductor was straightened only once for the application of the glass tape and wound directly afterwards. Regular geometrical checks were performed with gauges to compare the calculated height and thickness with the achieved geometry. 


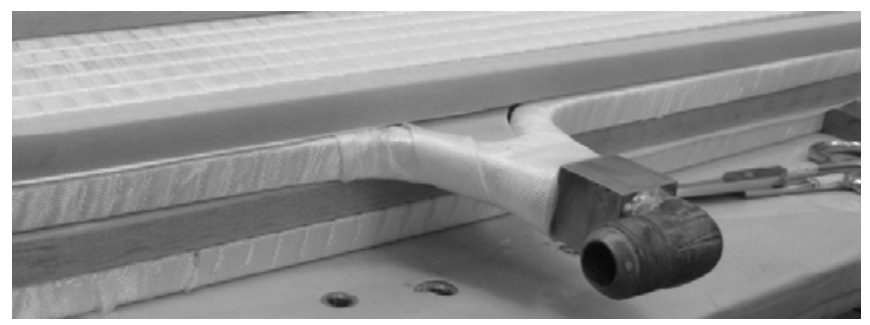

Fig. 2. Braze joint and filler at the pancake crossover.

The end of each conductor is brazed to either a fitting or to a layer-to-layer cross-over assembly (Fig. 2). The quality of the braze joint was checked by visual inspection and a leak check in which the joint was under tension and the conductor was pressurized with helium at 50 bar and a leak detector measured the leak rate outside of the conductor in a plastic bag. The acceptance criterion is a leak rate lower than $1 \mathrm{E}-6 \mathrm{mbar} 1 / \mathrm{s}$.

The turn-to-turn as well as the layer-to-layer insulation is comprised of S-2 glass tape with standard silane finish. After a layer was wound the electrical resistance was measured directly afterwards. The resistance and the inductance were measured also after a coil was completed. The measurements were done prior and after impregnation. It was checked that the coil meets the specified values but also that all type A coils are similar. The high voltage integrity was measured also before and after impregnation. The tests before impregnation comprises a DC voltage test to ground at $500 \mathrm{~V}$ and a surge test at $800 \mathrm{~V}$ that means a turn to turn voltage of $16 \mathrm{~V}$.

In addition hydraulic tests were performed. First a hydrostatic test was done with a pressure of 25 bar for ten minutes. No pressure change should occur. Afterwards a flow test was done. The water flow rate was measured separately of each of the eight layers with the un-used discharge paths closed. The inlet pressure for one discharge path was set to 13.8 bar and the outlet pressure to 8.5 bar, which results in a 5.3 bar pressure drop across the discharge path. These values simulate the static pressure and the expected pressure drop during operation of the coil in W7-X. The flow rate of a single pancake should be at least 0.194 $1 / \mathrm{s}$, and at most $0.214 \mathrm{l} / \mathrm{s}$. The above mentioned tests were repeated after the impregnation. It turned out that the flow rates per pancake are generally lower than calculated by about $5 \%$. The flow rates are between $0.185 \mathrm{l} / \mathrm{s}$ and $0.208 \mathrm{l} / \mathrm{s}$. The flow rates between the pancakes within a coil differ by not more than $4 \%$ from each other, which is acceptable. The measurements before and after impregnation have shown only small differences.

The total flow rates per coil are calculated to be 5.7 and 6.8 cubic meter per hours for type A and type B, respectively. After arrival at IPP the flow rates per coil were measured. Also in these tests the flow rates were slightly lower than calculated. The type A coils show flow rates between 5.1 and 5.3 cubic meter per hours and the type B coil has a flow rate of 6.6 cubic meter per hours.

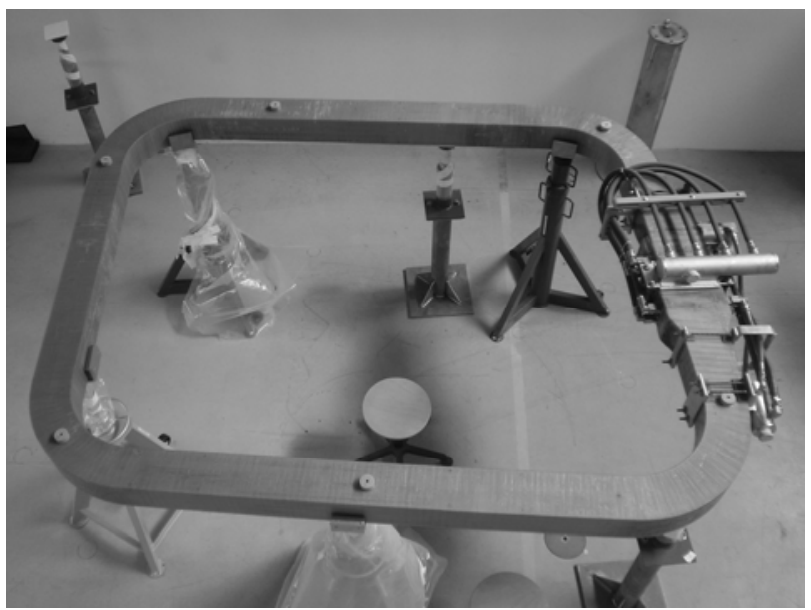

Fig. 3. Coil type B after arrival at IPP.

In addition the electrical tests were expanded by adding a high potential test to ground. The coil was wrapped with aluminum foil and a voltage of $2 \mathrm{kV}$ DC between the coil and the ground plane was applied.

When the leakage current has settled the steady state leakage current was measured and was less than two microamperes. The turn-to-turn insulation was measured, too. A surge voltage of $800 \mathrm{~V}$ peak was applied to the both ends of the coil before and after impregnation. The recorded waveforms of voltage and current demonstrated the proper function of the insulation.

Finally the coil geometry was measured with a laser tracker to compare the as build geometry with the designed geometry. All coils are within the allowed tolerance of $5 \mathrm{~mm}$ in radial and axial direction. 


\section{INSTALLATION OF THE TRIM COILS}

The coils (Fig. 3 shows the type B coil) are being mounted on the outer surface of the W7-X cryostat. Five support (type A coils) or four support (type B coil) positions at the coil were defined.

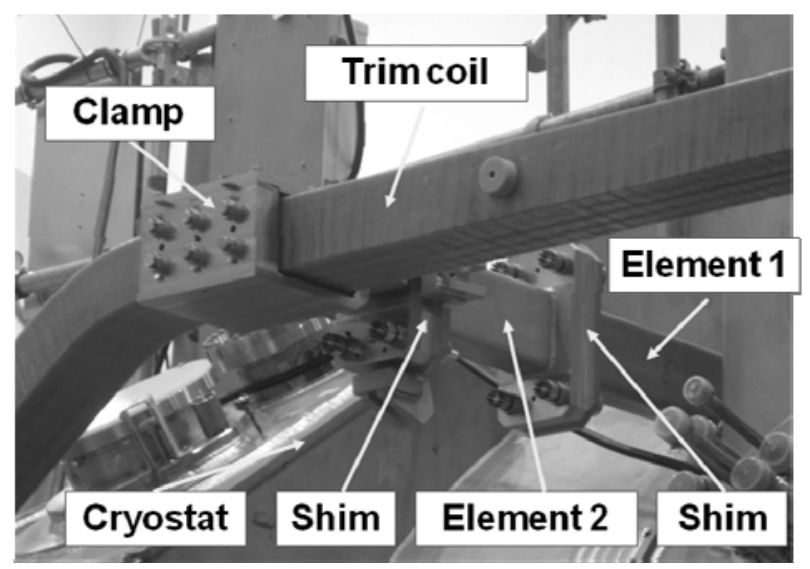

Fig. 4. A trim coil support with the three main elements.

Unfortunately the positions could not be defined according to the optimum for coil stability. Several positions had to be used, because they are the only possibility to place the support without clashing with other ports, diagnostics or pipes and cables during assembly and operation. The support system at each position consists of three main parts: the first part is a rectangular stainless steel beam with a base plate which is welded to the cryostat. The second element is connected by screws to element one. The important feature is a shim between these two elements. With the shim the deviations, which will occur during the welding of element one to the cryostat, can be corrected in radial direction and with the screws using slot hole also in axial direction.

The third element of a support system is the clamp, which is connected directly to the coil and holds the coil in position. At the connection between elements two and three also a shim and slot holes are present. The final dimension of the shim will be defined when the coils geometry is measured and based on this the best coil position with respect to the magnetic field has been defined. The clamp itself is equipped with pads made of rubber to allow the thermal expansion of the coil body during operation. Fig. 4 shows all the three elements of a support system in its final position after assembly of the third coil.

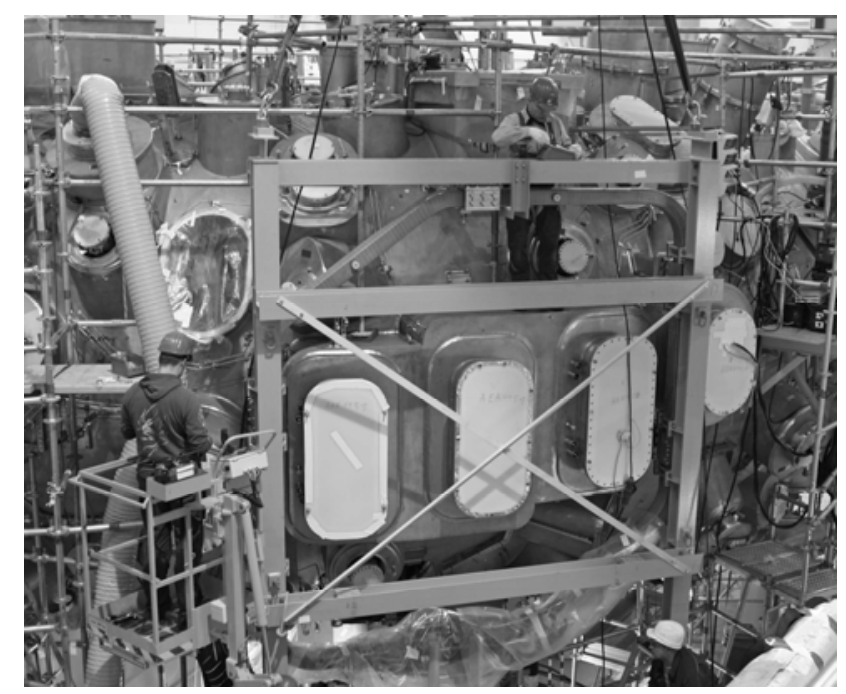

Fig. 5. Frame with a trim coil type A during assembly.

A trim coil type A body has a relatively lean cross section of 110x151 mm, compared with its overall dimensions. Therefore it has to be supported during all steps of the assembly in order to prevent unwanted bending due to its dead weight. Therefore the coil was connected to a massive steel frame for transportation and assembly. This frame remained until the coil had been fixed to the final supports at the cryostat. Fig. 5 shows a coil during assembly. 


\section{POWER SuPPLIES}

\section{A. Concept}

The power supply system consists of five power supply units, five safety disconnect switches (SDS), one low voltage distribution system, one cooling plant and one common central control system. PPPL is providing to W7-X the power supplies, the SDSs, high power cables and the local controls. IPP will design, procure and install the central control, the central cooling water unit, cabling and raceways to the coils. The electrical parameters from trim coil type B differ significantly from the ones of the type A coils. Nevertheless for economical and flexibility reasons five equal power supply units were ordered. The output voltage was set to $230 \mathrm{~V}$ in order to achieve the required ramp rate of up to $2.2 \mathrm{kA} / \mathrm{s}$ (see Table 2). The four quadrant converter allows zero crossing of the current during the plasma experiments of W7-X.

The power supply units will be connected to the IPP's cooling circuit. Therefore a dedicated power supply cooling plant with pumps and a heat exchanger have been designed. The total cooling power will be about $100 \mathrm{~kW}$. The direct cooling of components under voltage de-ionized requires water with a conductivity of less than $10 \mu \mathrm{S} / \mathrm{cm}$.

TABLE 2 FINAL DESIGN PARAMETERS OF A POWER SUPPLY

\begin{tabular}{cc}
\hline \hline Designation & Type A and B Coil \\
\hline Maximum output voltage & $\pm 230 \mathrm{~V}$ \\
Maximum current & $\pm 2200 \mathrm{~A}$ \\
Current control range & $-2.2 \mathrm{kA} \ldots+2.2 \mathrm{kA}$ \\
Maximum ramp rate & $2200 \mathrm{~A} / \mathrm{s}$ \\
Maximum power loss & $20 \mathrm{~kW}$ \\
Current control accuracy & $\pm 10 \mathrm{~A}$ \\
Long term stability of current $(30 \mathrm{~min})$ & $\pm 10 \mathrm{~A}$ \\
Residual ripple of current & $5 \mathrm{~A}_{\mathrm{SS}}$ \\
Dimensions (W x D x H) & $1.4 \times 1.4 \times 2.1[\mathrm{~m}]$ \\
weight & $2600 \mathrm{~kg}$ \\
\hline \hline
\end{tabular}

To separate each trim coil from the power supply a safety disconnect switch is connected at the output of every power supply. This switch will connect the coils to the ground while not operated with current to prevent induced voltages in the coils in case of current changes in the main magnetic field. Also the coil can be completely separated to allow measurements at the open coils terminals. Switch settings will be sent via read out contacts to the power supplies control to be integrated in the interlock and safety system.

\section{B. Fabrication and Tests}

The five power supply units were ordered by PPPL from Applied Power Systems (APS), Inc., of Hicksville, NY, U.S.A. The final electrical scheme is shown in Fig. 6. Each power supply unit consists of a $400 \mathrm{~V}$ input grid transformer of $450 \mathrm{kVA}$ which has at its secondary side two three phase systems at $192 \mathrm{~V}$ each, shifted by 30 degrees (electrically) to each other, followed by two diode six pulse bridges creating a DC bus of $260 \mathrm{~V}$, buffered with capacitors of $268 \mathrm{mF}$. The power conversion is being made by H-bridges using Insulated-Gate-Bipolar-Transistors (IGBT) with internal freewheeling diode. Three of these bridges are connected in parallel forming a subassembly. Four of these subassemblies are connected in parallel. A sophisticated current control loop and inductors in each H-bridge are being used to secure a parallel distribution of the current.

The input transformer, the rectifier diodes and the chill plates of the H-bridges are water cooled.

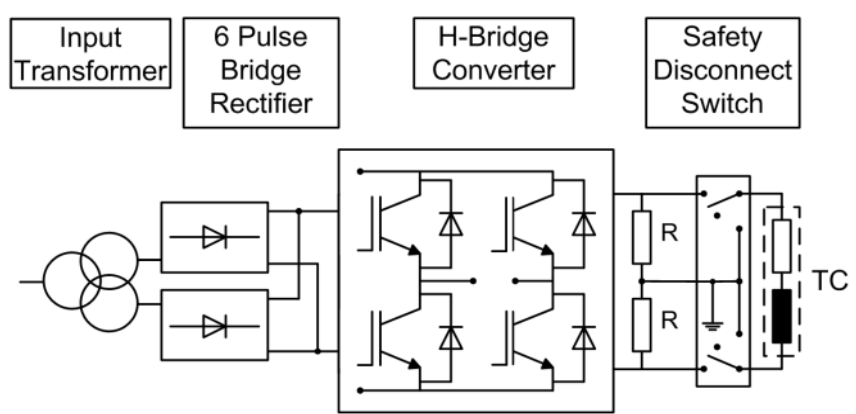

Fig. 6. Electrical scheme of the power supply $(\mathrm{TC}=$ Trim Coil; $\mathrm{R}=$ Ground resistor $)$. 
Among other test during the fabrication, tests at full current are being performed at the completed power supply. In order to test the output parameters, a $100 \mu \mathrm{H}, 170 \mu \Omega$ load will be placed across the output. The power supply will be run into this load for a minimum of 30 minutes at $2.2 \mathrm{kA}$ to verify that the output current stays within $+/-10 \mathrm{Amps}$, including ripple, of the set point current. The same dummy load will be used to perform a temperature rise test.

\section{CONCLUSION}

Wendelstein 7-X will be equipped with five trim coils for enhanced experimental flexibility and error field corrections. The coils, made of copper, are placed at the outer side of the cryostat. Five four-quadrant operating power supplies will be used to energize the coils. The manufacturing of the coils was finished in spring 2013. The installation at W7-X is well advanced. Three coils have been installed at their final place. The production of the power supplies is in progress. The first acceptance test of the first power supply is scheduled for summer 2013.

\section{ACKNOWLEDGMENT}

The collaboration in the design of the coils between IPP and the US associations Princeton Plasma Physics Laboratory and Oak Ridge National Laboratory as well as the funding provided by the U.S. Department of Energy is gratefully acknowledged. The authors would like to thank also all the involved colleagues for their work and co-operation.

\section{REFERENCES}

[1] J. Kißlinger and T. Andreeva, "Correction possibilities of magnetic field errors in Wendelstein 7-X,“ Fusion Engineering and Design 74 (2005), pp. 623626

[2] S. Freundt, "FE analyses and tests in support of Wendelstein $7 \mathrm{X}$ trim coil development," Fusion Engineering and Design (2013), http://dx.doi.org/10.1016/j.fusengdes.2013.02.031.

[3] N.A. Munshi, J.K. Walsh, M.W. Hooker, H.K. Babcock, A.H. Haight; S.R. Durso, A. Kawaguchi, P. Hough, "Radiation resistant electrical insulation qualified for ITER TF coils," IEEE Transactions on Applied Superconductivity, Volume: 23 , Issue: 3 (2013), Part: 3, Digital Object Identifier: 10.1109/TASC.2012.2231723, Article\#: 7700104.

[4] K. Riße, Th. Rummel, S. Freundt, A. Dudek, S. Renard, V. Bykov, M. Köppen, S. Langish, G.H. Neilson, Th. Brown, J. Chrzanowski, M. Mardenfeld, F. Malinowski, A. Khodak, X. Zhao, G. Eksaa, "Design and manufacturing status of trim coils for the Wendelstein 7-X stellarator experiment," Fusion Engineering and Design (2013), http://dx.doi.org/10.1016/ j.fusengdes.2013.02.045. 